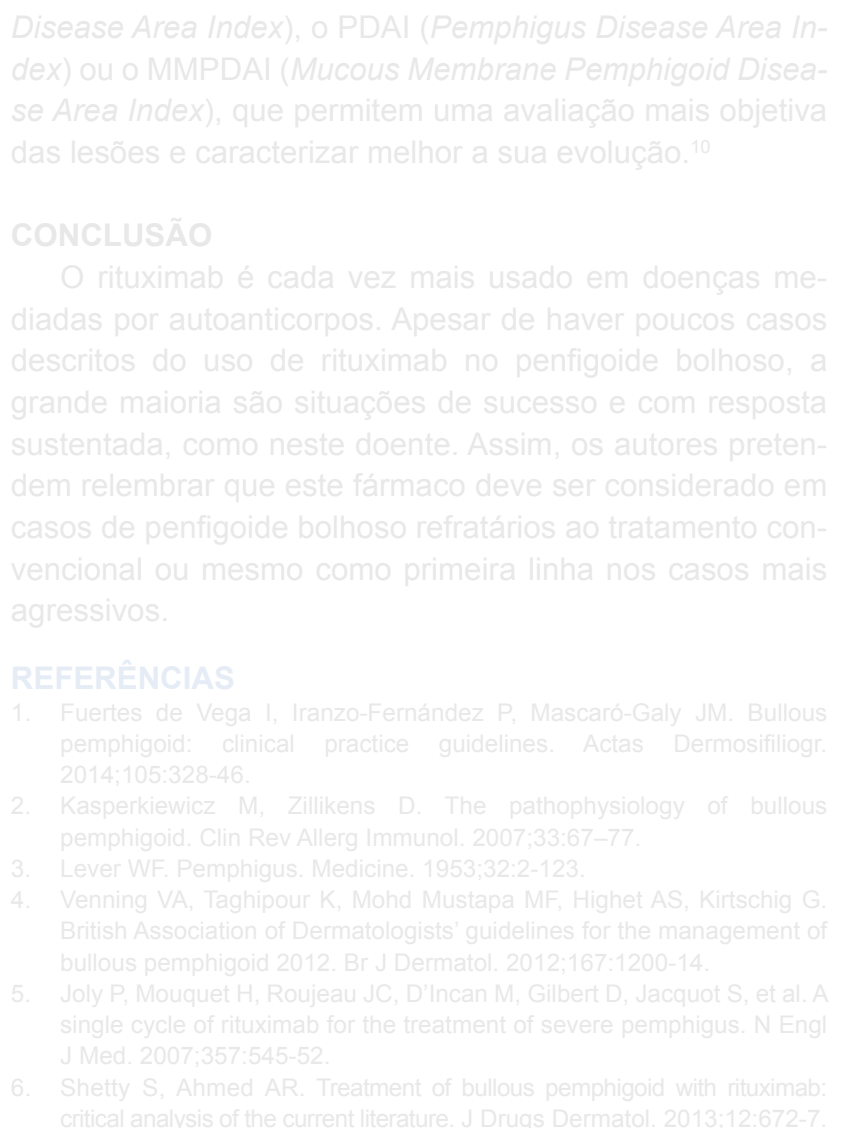

\title{
Doença Intersticial Pulmonar Grave e Mania Induzida por Corticosteróides em Doente com Lúpus Eritematoso Sistémico e Síndrome de Sjögren Secundária
}

\author{
Severe Interstitial Lung Disease and Manic Symptoms \\ Secondary to Corticosteroids in a Patient with Systemic \\ Lupus Erythematosus and Secondary Sjögren's \\ Syndrome
}

Sofia Silvério SERRA ${ }^{1}$, Teresa PEDROSA ${ }^{1,2}$, Sandra FALCÃO ${ }^{1,2}$, Jaime Cunha BRANCO ${ }^{1,2}$ Acta Med Port 2017 Mar;30(3):246-250 - https://doi.org/10.20344/amp.7297

\section{RESUMO}

A doença intersticial pulmonar ocorre em até cerca de $25 \%$ dos doentes com síndrome de Sjögren e em $2 \%$ - $8 \%$ dos doentes com lúpus eritematoso sistémico. Os corticosteróides permanecem como pilar de tratamento do lúpus eritematoso sistémico mas podem associar-se a complicações neuropsiquiátricas, sobretudo com doses de prednisolona superiores a $40 \mathrm{mg} / \mathrm{dia}$. Apresentamos o caso de uma doente de 51 anos com síndrome depressiva, lúpus eritematoso sistémico e síndrome de Sjögren secundária que desenvolveu envolvimento pulmonar grave evidente quatro anos após o diagnóstico, com tomografia computadorizada de tórax a revelar padrão de neofibrose e vidro despolido. Com o aumento da prednisolona para $60 \mathrm{mg} / \mathrm{dia}$ a doente iniciou um quadro maníaco com necessidade de internamento e que foi admitido no contexto de corticoterapia em dose elevada. Foi excluído envolvimento neurológico central por doença orgânica. Iniciou ciclofosfamida endovenosa mensal durante seis meses seguida de micofenolato de mofetil, tendo-se reduzido prednisolona até $10 \mathrm{mg} / \mathrm{dia}$ e mantido hidroxicloroquina $400 \mathrm{mg} / \mathrm{dia}$, com controlo da atividade da doença.

1. Serviço de Reumatologia. Hospital de Egas Moniz. Centro Hospitalar de Lisboa Ocidental. Lisboa. Portugal.

2. CEDOC. NOVA Medical School/Faculdade de Ciências Médicas. Universidade NOVA de Lisboa. Lisboa. Portugal.

$\square$ Autor correspondente: Sofia Silvério Serra. sofiaserra@sapo.pt

Recebido: 09 de dezembro de 2015 - Aceite: 12 de setembro de 2016 | Copyright @ Ordem dos Médicos 2017 
Palavras-chave: Corticosteroides/efeitos adversos; Doença Intersticial Pulmonar; Lúpus Eritematoso Sistémico; Perturbações Mentais/induzido quimicamente; Síndrome de Sjögren

\section{ABSTRACT}

Interstitial lung disease occurs in up to $25 \%$ of patients with Sjögren's syndrome and $2 \%-8 \%$ of patients with systemic lupus erythematosus. Corticosteroid therapy remains the main treatment for systemic lupus erythematosus. However, it can be associated with several neuropsychiatric disorders especially with prednisolone at a dose of more than $40 \mathrm{mg} /$ day. We present the case of a 51-year-old patient with systemic lupus erythematosus and secondary Sjögren's syndrome with severe pulmonary involvement four years after the diagnosis. Chest computed tomography revealed neofibrosis and ground glass appearance pattern. After increasing the dose of prednisolone to $60 \mathrm{mg} /$ day, the patient presented a manic episode. There was need of hospitalization and the situation was considered to be secondary to corticosteroids at high doses. Central neurological involvement by organic disease was excluded. We introduced monthly perfusion of cyclophosphamide for six months and later started mycophenolate mofetil 2 g/day, reducing prednisolone to $10 \mathrm{mg} /$ day and maintaining hydroxychloroquine $400 \mathrm{mg} / \mathrm{day}$, with control of disease activity.

Keywords: Adrenal Cortex Hormones/adverse effects; Lung Diseases, Interstitial; Lupus Erythematosus, Systemic; Mental Disorders/ chemically induced; Sjögren's Syndrome

\section{INTRODUÇÃo}

A combinação de lúpus eritematoso sistémico (LES) síndrome de Sjögren (SS) parece ter menor envolvimento de órgão major e desfecho clínico mais favorável que o LES isoladamente. ${ }^{1}$ Nos doentes com LES e/ou SS a doença intersticial pulmonar (DIP) é dominada por inflamação e/ou fibrose. As formas fibrosantes apresentam fraca resposta à terapêutica e significativa morbi-mortalidade. ${ }^{2}$ A DIP sobretudo com fibrose desenvolve-se em aproximadamente $25 \%$ dos doentes com SS. ${ }^{2}$ A terapêutica envolve corticosteroides (dose moderada/alta), frequentemente em combinação com ciclofosfamida ou azatioprina. ${ }^{3,4,5}$ Após seis a doze meses de ciclofosfamida é feita transição para azatioprina ou micofenolato de mofetil (MMF). ${ }^{3}$ A experiência é limitada com inibidores do factor de necrose tumoral (anti-TNF) ou rituximab. ${ }^{2,6} \mathrm{Na}$ ausência de linhas de orientação específicas para a DIP nas doenças do tecido conjuntivo, a experiência adquirida em relatos de casos é essencial.

No LES e SS as perturbações do humor (sobretudo depressão, hipomania e psicose) são mais sugestivas de efeito adverso da corticoterapia (sobretudo com prednisolona $>40 \mathrm{mg} / \mathrm{dia}$ ) do que de envolvimento do sistema nervoso central (SNC) ${ }^{7,8,9}$

\section{CASO CLÍNICO}

Apresentamos o caso de uma doente de 51 anos, caucasiana, com síndrome depressiva (medicada com mirtazapina $45 \mathrm{mg} / \mathrm{dia}$ e clomipramina $150 \mathrm{mg} / \mathrm{dia}$ ) e desde 2008 seguida em Reumatologia por LES e SS secundária. Apresentou-se com fadiga, fotossensibilidade, eritema no tronco, xeroftalmia, xerostomia, fenómeno de Raynaud grave e poliartralgias inflamatórias, simétricas e aditivas das pequenas articulações das mãos com tumefacção e rigidez matinal prolongada. Laboratorialmente destacava-se linfopenia, função renal normal sem proteinúria, anticorpos anti-nucleares (ANAs) positivos (título 1/640) e anticorpos anti-SS-A/Ro e anti-SS-B/La positivos. A cintigrafia das glândulas salivares era compatível com SS e a radiografia de tórax normal. Instituiu-se hidroxicloroquina $400 \mathrm{mg} / \mathrm{dia}$, prednisolona $5 \mathrm{mg} / \mathrm{dia}$, pentoxifilina e antiagregação plaquetária, com boa resposta clínica.

Em 2009 não tinha queixas respiratórias, mas na auscultação pulmonar apresentava crepitações bibasais e radiologicamente tinha reforço intersticial basal direito. Rea- lizou tomografia computadorizada (TC) pulmonar em julho 2009 que revelou bronquiectasias de tracção, padrão reticular bibasal com escassas imagens sugestivas de vidro despolido na base direita. As provas de função respiratória (PFR) não mostraram alterações. Pela evidência de DIP em atividade aumentou-se prednisolona para $60 \mathrm{mg} / \mathrm{dia}$ durante um mês. Posteriormente foi introduzida azatioprina em dose crescente até $150 \mathrm{mg} /$ dia e reduziu-se a prednisolona até $10 \mathrm{mg} / \mathrm{dia}$.

Em 2010 repetiu TC tórax e PFR com resultados estáveis. Em 2012 iniciou tosse não produtiva e cansaço, sem febre. Na auscultação pulmonar, com murmúrio vesicular diminuído e fervores subcrepitantes bibasais. Cumpriu diversos ciclos de antibioterapia com amoxicilina/ácido clavulânico e claritromicina, sem melhoria. Laboratorialmente apresentava hemoglobina $11,3 \mathrm{~g} / \mathrm{dL}$, ausência de leucocitose ou neutrofilia, velocidade de sedimentação (VS) de $64 \mathrm{~mm} / \mathrm{h}$ e proteína C reactiva (PCR) de $0,81 \mathrm{mg} /$ $\mathrm{dL}$. A gasimetria arterial não estava alterada e o teste de Mantoux era anérgico.

Em Fevereiro de 2013 repetiu TC tórax que evidenciou padrão de neofibrose, bronquiectasias retrácteis, atelectasias subsegmentares e padrão de alveolite (vidro despolido). As PFR continuaram sem alterações. A broncofibroscopia revelou discretos sinais de bronquite, exame citológico, directo e cultural para bactérias e micobactérias sem alterações. Aumentou-se prednisolona para $60 \mathrm{mg} /$ dia, mantendo-se a restante terapêutica.

Um mês depois surgiram alterações do comportamento (ideias de grandeza, heteroagressividade e insónia). Não apresentava sinais neurológicos focais e o estudo citológico, bioquímico e bacteriológico do líquor não revelou alterações. Na ressonância magnética crânio-encefálica apenas tinha sela turca parcialmente vazia, sem manifestações de disfunção hipofisária. Com avaliação psiquiátrica e ausência de evidência de doença orgânica admitiu-se quadro de mania secundário à corticoterapia. Após início de terapêutica estabilizadora do humor e redução da dose de corticosteróide, assistiu-se a boa evolução psicopatológica, com regressão das ideias de grandeza e da heteroagressividade e normalização do padrão do sono.

O quadro respiratório mantinha-se, a gasimetria arterial continuava normal, mas a radiografia de tórax apresentava 
padrão intersticial retículo-nodular de predomínio bibasal (Fig. 1). Laboratorialmente, objetivou-se diminuição da hemoglobina (10,6 $\mathrm{g} / \mathrm{dL})$, trombocitose (496 $\left.000 \times 10^{6} / \mathrm{L}\right)$, VS $50 \mathrm{~mm} / \mathrm{h}$, PCR $1,35 \mathrm{mg} / \mathrm{dL}$, proteinúria (520,8 mg/24 h), depuração de creatinina normal e hemoculturas negativas. A imunologia revelou adicionalmente ausência de anticorpos anti-DNAds em título significativo e doseamento normal dos fatores de complemento. Iniciou-se ciclofosfamida (750 $\mathrm{mg} / \mathrm{m}^{2}$ ), mantendo prednisolona $12,5 \mathrm{mg} /$ dia e hidroxicloroquina $400 \mathrm{mg} / \mathrm{dia}$.

Cumpriu ciclofosfamida endovenosa mensal durante seis meses e depois terapêutica de manutenção com MFM ( $2 \mathrm{~g} / \mathrm{dia}$ ) e prednisolona (10 mg/dia). Na TC tórax de controlo (junho 2014, Fig. 2) eram evidentes extensas áreas em vidro despolido sobretudo nos lobos inferiores em relação com fibrose estabelecida, e imagens quísticas subpleurais. As PFR revelaram alteração restritiva grave (FCV 35\%; FEV1 36\%, Tiff 87\%; TLC 46\%; VR 37\%) e diminuição da capacidade de difusão de CO (DLCO 19\%). A gasimetria em ar ambiente revelou insuficiência respiratória parcial (pH 7,41; pCO2 45; pO2 52; HCO3- 28,5; SatO2 87\%), pelo que iniciou oxigenoterapia de longa duração (OLD).

Desde então manteve-se clinicamente estável medica- da com hidroxicloroquina $400 \mathrm{mg} / \mathrm{dia}$, prednisolona $10 \mathrm{mg} /$ dia, carbonato de cálcio + colecalciferol 1500 mg + $400 \mathrm{UI}$, ácido alendrónico $70 \mathrm{mg} / \mathrm{semana}$, MFM $2 \mathrm{~g} / \mathrm{dia}$, quetiapina $25 \mathrm{mg} / \mathrm{dia}$, clomipramina $75 \mathrm{mg} / \mathrm{dia}$ e OLD a $2 \mathrm{~L} / \mathrm{min}$.

\section{DISCUSSÃO}

Os autores reportam um caso de associação LES-SS com envolvimento pulmonar rapidamente progressivo para fibrose que se desenvolveu sob imunossupressão mas foi estabilizado após alteração para ciclofosfamida seguida de MFM, com possibilidade de redução da dose de corticosteróide.

As recomendações de tratamento do envolvimento pulmonar grave nos doentes com LES e SS são escassas e baseiam-se essencialmente em relatos pontuais de um número reduzido de doentes. Foram reportados efeitos benéficos da ciclofosfamida na DIP, com melhoria sintomática, funcional, radiológica, inflamatória (no lavado broncoalveolar) e de sobrevivência. ${ }^{2}$ Shi JH et al, 2009 reportaram estabilização ou melhoria da função respiratória com prednisolona e ciclofosfamida em 14 doentes com SS. ${ }^{10} \mathrm{~A}$ terapêutica de manutenção com MFM demonstrou, nalguns estudos, efeito poupador de corticóide e manutenção ou

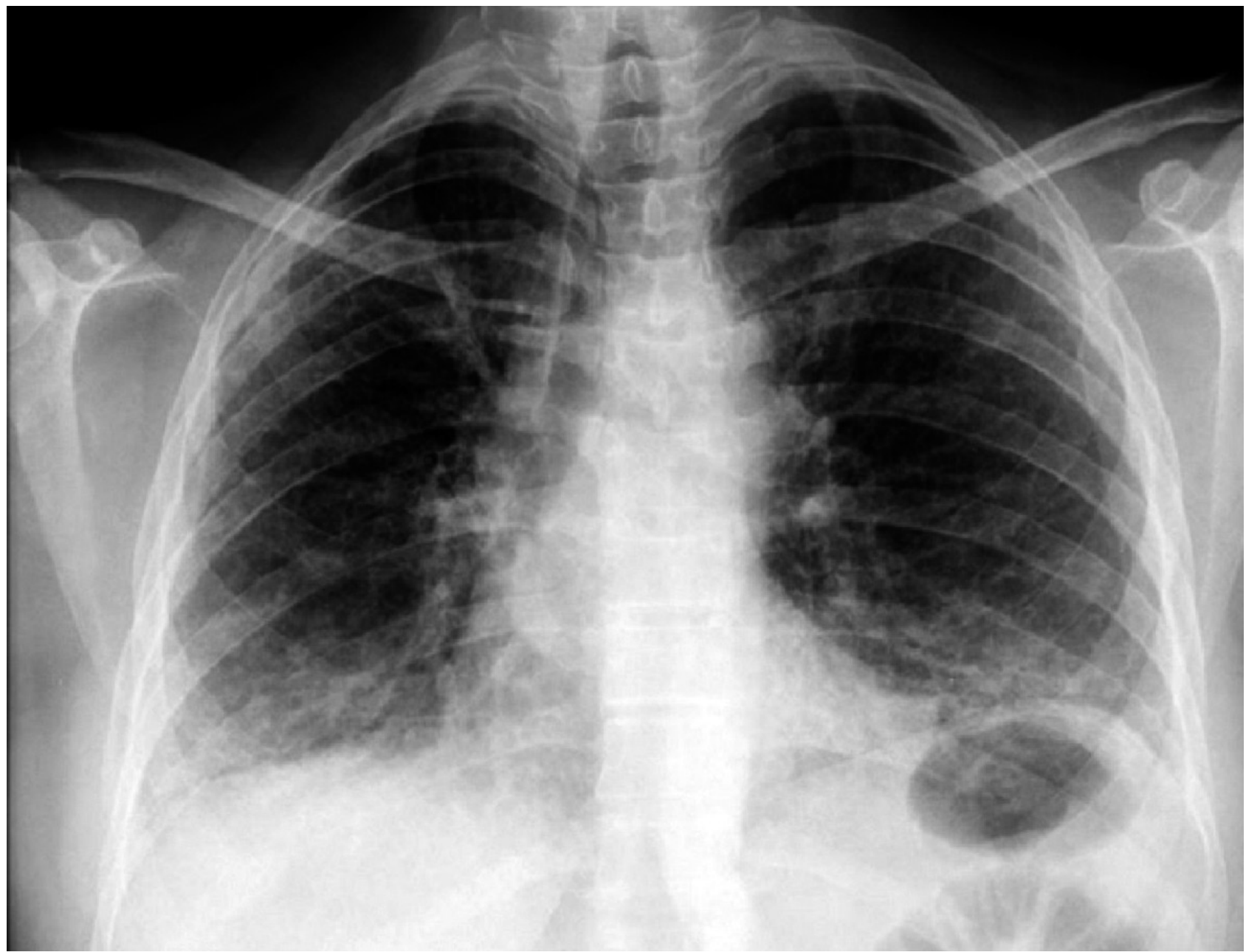

Figura 1 - Telerradiografia de tórax ântero-posterior (março de 2014) que evidencia padrão intersticial retículo-nodular com predomínio em ambas as bases pulmonares 


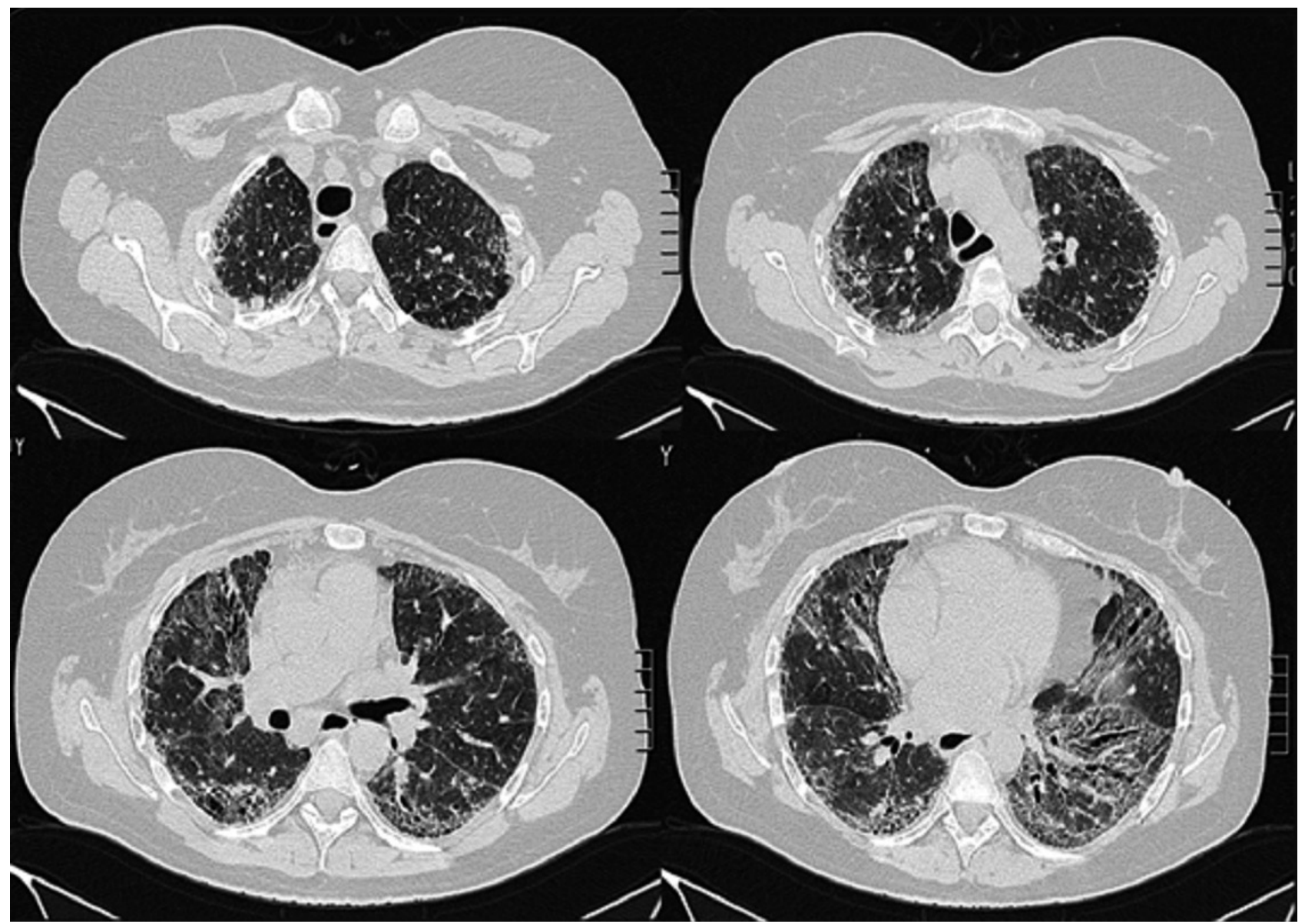

Figura 2 - Tomografia computadorizada de tórax (junho de 2014), em cortes transversais, que revela extensas áreas em vidro despolido, sobretudo nos lobos inferiores, em relação com fibrose já estabelecida, e imagens quísticas periféricas subpleurais

\section{melhoria da fisiologia pulmonar. ${ }^{3,11}$}

Neste caso, a relação das manifestações psiquiátricas com a subida da dose de corticosteróide e a exclusão de patologia orgânica do SNC foram essenciais para diagnosticar mania/psicose associada aos corticosteróides.

Apesar do reduzido número de casos semelhantes reportados, é importante procurar abordagens mais específicas para seguimento e tratamento do envolvimento pulmonar nas doenças do tecido conjuntivo.

\section{REFERÊNCIAS}

1. Yao Q, Altman RD, Wang X. Systemic lupus erythematosus with Sjögren syndrome compared to systemic lupus erythematosus alone: a metaanalysis. J Clin Rheumatol. 2012;18:28-32.

2. Castelino F, Varga J. Interstitial lung disease in connective tissue diseases: evolving concepts of pathogenesis and management. Arthritis Res Ther. 2010;12:213-22.

3. Wells $A U$, Hirani $\mathrm{N}$ on behalf of the British Thoracic Society Interstitial Lung Diseas Guideline Group, a subgroup of the British Thoracic Society Standards of Care Committee, in collaboration with the Thoracic Society of Australia and New Zealand and the Irish Thoracic Society. Interstitial lung disease guideline: the British Thoracic Society in collaboration with the Thoracic Society of Australia and New Zealand and the Irish Thoracic Society. Thorax. 2008;63:v1-58.

4. Vij R, Strek ME. Diagnosis and treatment of connective tissue diseaseassociated interstitial lung disease. Chest. 2013;143:814-24.

5. Parambil JG, Myers JL, Lindell RM, Matteson EL, Ryu JH. Interstitial lung disease in primary Sjögren syndrome. Chest. 2006;130:1489 -95.

6. Keir GJ, Maher TM, Hansell DM, Denton CP, Ong VH, Singh S, et al.

\section{CONFLITOS DE INTERESSE}

Os autores declaram não terem qualquer conflito de interesse relativamente ao presente artigo.

\section{FONTES DE FINANCIAMENTO}

Os autores declaram não ter recebido subsídios ou bolsas para a elaboração do artigo.

Severe interstitial lung disease in connective tissue disease: rituximab as rescue therapy. Eur Respir J. 2012;40:641-8.

7. Nishimura K, Omori M, Sato E, Katsumata Y, Gono T, Kawaguchi Y, et al. New-onset psychiatric disorders after corticosteroid therapy in systemic lupus erythematosus: an observational case-series study. J Neurol. 2014;261:2150-8.

8. West S, Kenedi C. Strategies to prevent the neuropsychiatric sideeffects of corticoesteroids: a case report and review of the literature. Curr Opin Organ Transplant. 2014;19:201-8.

9. Bhangle SD, Kramer N, Rosenstein ED. Corticosteroid-induced neuropsychiatric disorders: review and contrast with neuropsychiatric lupus. Rheumatol Int. 2013;33:1923-32.

10. Shi JH, Liu HR, Xu WB, Feng RE, Zhang ZH, Tian XL, et al. Pulmonary manifestations of Sjögren's syndrome. Respiration. 2009;78:377-86.

11. Fischer A, Brown KK, Du Bois RM, Frankel SK, Cosgrove GP Fernandez-Perez ER, et al. Mycophenolate mofetil improves lung function in connective tissue disease-associated interstitial lung disease. J Rheumatol. 2013;40:640-6. 
12. Deheinzelin D, Capelozzi VL, Kairalla RA, Barbas Filho JV, Saldiva PH, de Carvalho CR. Interstitial lung disease in primary Sjögren's syndrome.
Clinical-pathological evaluation and response to treatment. Am J Respir Crit Care Med. 1996;154:794-9. 